Academic Platform Journal of Engineering and Science

\title{
TIG Kaynak Yöntemiyle Birleştirilmiş Alüminyum 1050 Alaşımının Mekanik Ve Mikroyapı Özellikleri
}

\author{
*1 Arife Kübra Demirbaş, ${ }^{2}$ Sinem Çevik \\ ${ }^{1}$ Ondokuzmayıs Üniversitesi, Metalurji ve Malzeme Mühendisliği Bölümü, 55210, Samsun, Türkiye, \\ akubrademirbas@gmail.com, \\ ${ }^{2}$ Ondokuzmayıs Üniversitesi, Metalurji ve Malzeme Mühendisliği Bölümü, 55210, Samsun, Türkiye, \\ scevik76@gmail.com,
}

Araştırma Makalesi

Geliş Tarihi: 08.11.2019

Kabul Tarihi: 07.07.2020

\section{$\ddot{O} \mathbf{z}$}

Alüminyum ve alüminyum alaşımları iyileştirilmiş mukavemet özelikleri, hafif olmaları, iyi ısıl ve elektrik iletkenlikleri, yüksek korozyon dirençleri nedeniyle gıda, kimya, otomotiv ve gemi inşa endüstrileri, taşıt, makina ve cihaz yapımı ile mimari alanda, inşaat, havacılık ve uzay endüstrilerinde çok geniş kullanım alanına sahiptirler ve bu alanların çoğunda alüminyumun kaynağ 1 uygulanmaktadır. TIG (Tungsten Inert Gas) kaynağı, ekonomik oluşu ve kolay uygulanabilir olması nedeniyle alüminyum ve alaşımlarının birleştirilmesinde tercih edilmektedir. Bu çalışmada Al 1050 alaşımı plakalar TIG kaynak yöntemi kullanılarak birleştirilmiştir. Kaynakla birleştirilmiş numunelere çekme testi uygulanmıştır ve çekme dayanımları ölçülmüştür. Kaynak bölgesi ve 1sı tesiri altındaki bölgelerin (ITAB) sertlik değerleri Vickers Sertlik testi uygulanarak incelenmiştir. Numunelerin kaynak uygulamasından sonraki ana metal, 1sı tesiri altındaki bölge ve kaynak bölgesi mikroyapıları optik mikroskop kullanılarak incelenmiştir. Elde edilen sonuçlar doğrultusunda Al 1050 alaşımının TIG kaynak işlemi sonrası mekanik özellikleri ve mikroyapısı tüincelenmiştir ve yorumlanmıştır.

Anahtar Kelimeler: Al 1050 alaşımı, tungsten inert gaz, kaynak, mekanik özellikler, mikroyapı

\section{Mechanical and Microstructure Properties of Aluminum 1050 Alloy Joined with TIG Welding Method}

\author{
*1 Arife Kübra Demirbaş, ${ }^{2}$ Sinem Çevik \\ ${ }^{1}$ Ondokuzmayıs University, Department of Metallurgical and Materials Engineering, 55210, Samsun, Turkey, \\ akubrademirbas@gmail.com \\ ${ }^{2}$ Ondokuzmay1s University, Department of Metallurgical and Materials Engineering, 55210, Samsun, Turkey, \\ scevik76@gmail.com
}

\begin{abstract}
Aluminum and aluminum alloys due to their improved strength properties, light weight, good thermal and electrical conductivity, high corrosion resistance, are widely used in food, chemical, automotive and shipbuilding industries, vehicle, machinery and equipment, architectural, construction, aerospace industries and in most of these areas the welding of aluminum is applied. TIG (Tungsten Inert Gas) welding is preferred for joining aluminum and its alloys due to its economical and easy application. In this study, Al 1050 alloy plates are joined using TIG welding method. Tensile tests were applied to welded samples and tensile strengths were measured. The hardness values of the weld zone and heat affected zones were examined by applying Vickers Hardness Test. The main metal, heat affected zone and welding zone microstructures were examined by using optical microscope. According to the results, mechanical properties and microstructure of Al 1050 alloy after TIG welding were investigated and interpreted.
\end{abstract}

Keywords: Al 1050 alloy, tungsten inert gas, welding, mechanical properties, microstructure

*Corresponding Author:Ondokuzmayis University, Department of Metallurgical and Materials Engineering, 55210, Samsun, Turkey, akubrademirbas@gmail.com 


\section{GİRIŞ}

Alüminyum ve alüminyum alaşımları iyileştirilmiş mukavemet özelikleri, hafif olmaları, iyi ısıl ve elektrik iletkenlikleri, yüksek korozyon dirençleri nedeniyle gıda, kimya, otomotiv ve gemi inşa endüstrileri, taşıt, makina ve cihaz yapımı ile mimari alanda, inşaat, havacılık ve uzay endüstrilerinde çok geniş kullanım alanına sahiptirler ve bu alanların çoğunda alüminyumun kaynağı uygulanmaktadır [1-4]. Saf alüminyum iyi ısıl iletkenliğine sahiptir ve oldukça yumuşak bir malzemedir. Alüminyumun özelliklerini değiştirmek için az miktarda alaşım elementi ilavesi yapmak yeterli olmaktadır. Teknolojik işlemlerden geçirilebilir ve araç-gereçler, yapısal elemanlar ve diğer ürünler için kullanılabilirler $[5,6]$. Alüminyum ve alaşımları, çeşitli kaynak yöntemlerini kullanırken dikkat edilmesi gereken bazı fiziksel ve kimyasal özelliklere sahiptir. Alüminyum alaşımlarının kaynak uygulamasındaki en ciddi problemlerden biri, kaynak havuzunda meydana gelen türbülans sırasında koruyucu gazlar, hava ve hidrojen gibi gazların sıkışmasından oluşan gözenekliliktir. Soğutma hızı çok yüksek olduğunda, bu gazlar kaynak havuzundan çıkamaz ve bu da kaynak bölgesinde gözenek oluşmasına neden olur. Aslında, tüm kaynaklanmış alüminyumlarda az miktarda gözeneklilik bulunmaktadır. Bunun nedeni, hidrojenin sıvı ve katı alüminyumdaki büyük çözünürlük farkı olmaktadır [7-10]. Bu olumsuz özelliğinin yanı sıra alüminyum ve alaşımlarının yüzeyi çok yüksek sıcaklıkta bir oksit tabakası ile kaplanmaktadır. Bu oksit tabakası çok sıkı bir şekilde yüzeyi sararak oksitlenmenin iç kısımlara doğru ilerlemesini önlemektedir. $\mathrm{Bu}$ oksit kaynak sicaklığında ergimediğinden kaynak dikişine doğru elektrotun ergimesi ile geçer ve kaynak bağlantısının sürekliliğini sağlayan damlacıkların bir araya gelmesine engel olur [11].

Alüminyum ve alaşımlarının sahip olduğu olumsuz kaynak uygulaması özelliklerinden dolayı kaynak işlemi ile birleştirilmelerinde meydana gelen hataların en aza indirilmesi için yapılacak olan çalışmalar oldukça önemlidir. Her alüminyum alaşımı sahip olduğu farklı kimyasal özelliklerinden dolayı kaynak işlemini sonrası meydana gelen yapısı da farklı olmaktadır. Geleneksel kaynak yöntemleri ya da her kaynak yöntemi alüminyum alaşımlarının hepsi için uygun olmayabilmektedir. Al 1050 alaşımı kolay şekillendirilebilen, yüksek korozyon direncine sahip ve mimari ve dekoratif uygulamalarda, kaplama levhalarında ve inşaat sektöründe oldukça yaygın kullanımı olan bir malzemedir [12]. Kullanım alanı çok yaygın olan bu alüminyum alaşımının kaynak uygulamaları ve kaynak sonrası kimyasal ve fiziksel özelliklerinin iyi bilinmesi gerekmektedir. Al 1050 alaşımının literatürde az sayıda TIG kaynak yöntemi kullanılarak yapılan deneysel çalışmaları bulunmaktadır. Alüminyum ve alaşımlarının birleştirilmesinde TIG kaynak yöntemi ekonomik olması, kolay uygulanabilirliği, kaliteli kaynak bölgesi elde edilmesi nedeniyle genellikle tercih edilmektedir [13-18]. Tungsten inert gaz (TIG) kaynağı, koruyucu gaz ortamında, tüketilemeyen bir tungsten elektrotu ile ana metal malzeme arasında oluşan bir ark ile metallerin isınarak birleşmesini sağlayan bir ark kaynağı işlemidir. TIG kaynak yöntemi; 1S1 girdisi yerel olduğu için 1sı iletim katsayısı yüksek olan alüminyum ve alaşımlarının kaynağında oluşan çarpılmaları en aza indirdiğinden çok tercih edilen bir gazaltı kaynak yöntemidir. TIG kaynağında, iki çeşit akım; doğru ya da alternatif akım kullanılabilir. Ancak alüminyum alaşımlarının kaynağında alternatif akım kullanılması gerekmektedir [19-21]. Normalde, negatif kutup (DCEN) olarak tungsten ile bir DC arkı kullanılmaktadır. Eğer iş parçası anot olarak kullanılırsa, oksit tabakasının bulunduğu alüminyum ve magnezyum gibi metaller için bu arkın kullanımı mümkün değildir. Bu katman kaynak havuzunun oluşumunu önlemektedir. Hareketli olan katod noktası oksit tabakasını dağıtabilir, ancak eğer anot olarak kullanılırsa tungsten elektrotunda aşırı 1sı üretimi olmaktadır [22].

Yapılan bu çalışmada Alüminyum 1050 alaşımı TIG kaynak yöntemi ile birleştirilmiştir. Birleştirilen numunelerin çekme dayanımları, kaynak bölgesi Vickers sertlik değerleri incelenmiştir. Optik mikroskopta birleşme bölgelerinin mikroyapıları incelenerek kaynak işleminin alaşımın mekanik özelliklerine olan etkisi mikroyapı ile ilişkilendirilerek yorumlanmıştır.

\section{MATERYAL VE YÖNTEM}

Çalışmada $4 \mathrm{~mm}$ kalınlıkta ve $65 \times 100 \mathrm{~mm}$ boyutlarındaki $\mathrm{Al}$ 1050 alaşım levhaları TIG kaynak yöntemi ile birleştirilmiştir. Kullanılan alaşımın ağırlıç̧a kimyasal bileşimi Tablo 1'de verilmiştir. Kaynak işlemi öncesi alüminyum alaşımların yüzeyinde bulunan ve kaynak sıcaklığında ergimeyen oksit tabakası paslanmaz çelik firça ile temizlenerek birleştirme sırasında bu tabakanın kaynak dikişine geçişi en aza indirilmiştir. Birleştirme için kullanılan kaynak parametreleri Tablo 2'de verilmiştir ve kaynak işlemi sonrası levha Şekil 1'de gösterilmiştir.

Tablo 1. Alüminyum 1050 alaşımının ağırlıkça kimyasal bileşimi (\%).

\begin{tabular}{|c|c|c|c|c|c|c|c|}
\hline $\mathrm{Fe}$ & $\mathrm{Si}$ & $\mathrm{Zn}$ & $\mathrm{Ti}$ & $\mathrm{Mg}$ & $\mathrm{Mn}$ & $\mathrm{Cu}$ & $\mathrm{Al}$ \\
\hline 0,4 & 0,25 & 0,07 & 0,05 & 0,05 & 0,05 & 0,05 & 99,5 \\
\hline
\end{tabular}

Tablo 2. Kaynak parametreleri.

\begin{tabular}{|c|c|c|c|c|}
\hline $\begin{array}{c}\text { Kaynak } \\
\text { Akımı }\end{array}$ & $\begin{array}{c}\text { Kaynak } \\
\text { Gerilimi }\end{array}$ & $\begin{array}{c}\text { Ark } \\
\text { Tipi }\end{array}$ & $\begin{array}{c}\text { Koruyucu } \\
\text { Gaz }\end{array}$ & $\begin{array}{c}\text { Dolgu } \\
\text { Teli }\end{array}$ \\
\hline $80 \mathrm{~A}$ & $7-8 \mathrm{~V}$ & Darbeli & Argon & Cr4043 \\
\hline
\end{tabular}

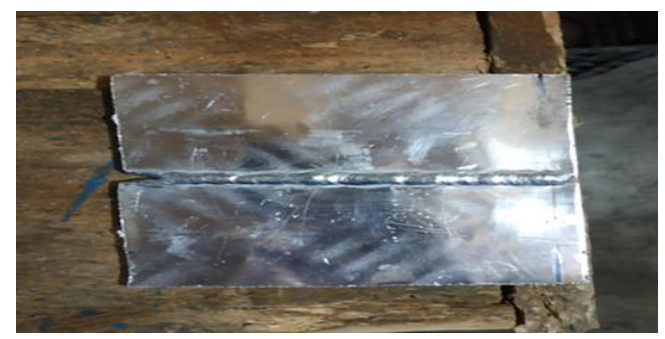

Şekil 1. TIG kaynak yöntemiyle birleştirilmiş levhaların görüntüsü. 
Kaynakla birleştirilen levhalara çekme testi ve Vickers sertlik testi uygulanmıştır. Kaynak bölgesi, 1sı tesiri altındaki bölge ve ana metal bölgesi mikroyapıları optik mikroskop altında incelenmiştir.

\section{1. Çekme Testi}

Çekme testleri 10-tone universal MARES çekme-basma test cihazından gerçekleştirilmiştir. 4x20x130 mm boyutlarındaki 4 adet numuneye çekme testi uygulanmıştır. Çekme testi uygulanan numuneler Şekil 2'de gösterilmiştir. Kaynak ile birleştirilen alaşımların çekme mukavemetleri incelenerek yorumlanmıştır.

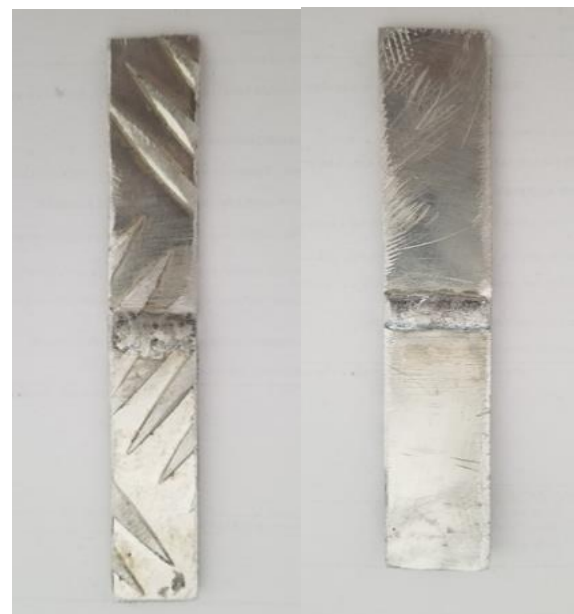

Şekil 2. Çekme testi için hazırlanan numuneler.

\subsection{Sertlik Testi}

Numunelerin sertlik değerleri TMTECK HV-1000B Mikro sertlik cihazı kullanılarak 15 sn süre ile $0.98 \mathrm{~kg}$ kuvvet uygulanarak $3 \mathrm{~mm}$ aralıklar ile ölçülmüştür. Kaynak bölgesi, 1S1 tesiri altındaki bölge ve ana metal bölgesi sertlik değerleri karşılaştırılarak kaynak işleminin alaşımın sertliğine olan etkisi incelenmiştir.

\subsection{Mikroyapı İncelemesi}

Kaynak işlemi sonra numunelerin kaynak bölgesi ve ITAB mikroyapıları Leica DM2500 P optik mikroskopu kullanılarak görüntülenmiştir. TIG kaynağının alaşımın mikroyapısına etkisi ve buna bağlı olarak numunelerin mekanik özelliklerindeki değişism yorumlanmıştır. Numuneler optik mikroskop incelemesinden önce Keller ayracı $(2 \mathrm{ml} \mathrm{HF}+3 \mathrm{ml} \mathrm{HCl}+5 \mathrm{ml} \mathrm{HNO} 3+190 \mathrm{ml} \mathrm{Su})$ kullanılarak $1 \mathrm{dk}$ süre ile dağlanmıştır. Dağlama işlemi sonrası numulerin ana metal bölgesi, kaynak bölgesi ve ITAB mikroyapısı görüntülenmiştir.

\section{BULGULAR}

\section{1.Çekme Testi Sonuçları}

Çekme testi uygulanan 3 numune birleşme bölgesinden(kaynak bölgesi) değil ısıdan etkilenen bölgeden kopmuştur. Çekme testi sonrası numune Şekil 3'te gösterilmiştir.

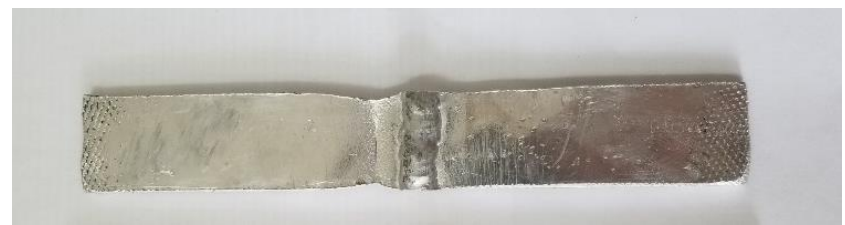

Şekil 3. Çekme testi sonrası numune.

Numunelerin gerilme değerleri Şekil 4'deki grafikte gösterilmiştir. Tüm numunelerin birbirlerine yakın değerlerde çekme gerilmesine sahip olduğu görülmüştür. 3 numunenin ortalama gerilme değeri Şekil 5'deki grafikte verilmiştir.

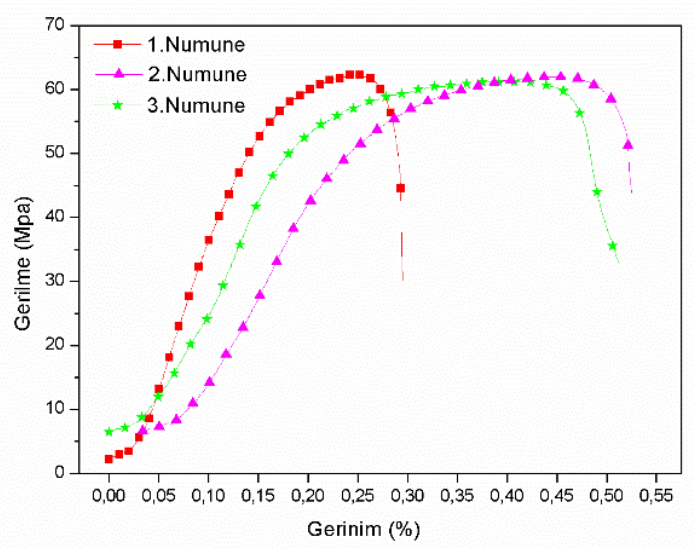

Şekil 4. Çekme testi uygulanan numunelerin gerilmegerinim grafiği.

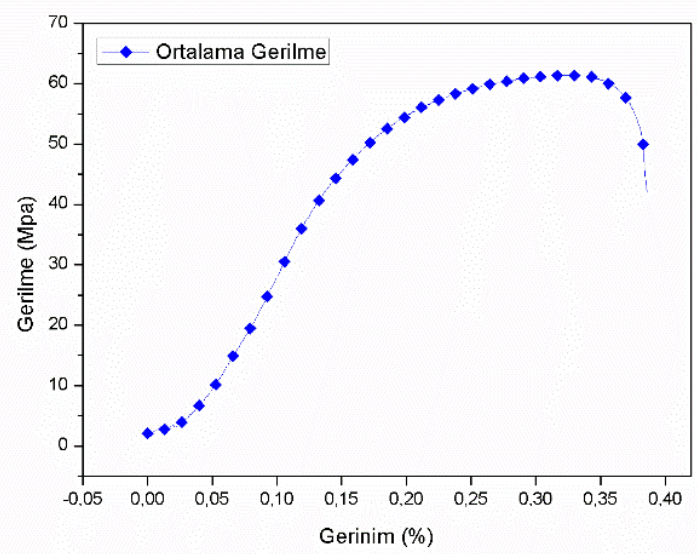

Şekil 5. Numunelerin ortalama gerilme-gerinim grafiği.

Numuneler sünek bir alaşım malzemesi olduğundan çekme işlemi sonrası numune boylarında uzaman meydana gelmiştir. Tüm numunlerin uzama(\%) değerleri Şekil 6'daki grafikte gösterilmiştir. 


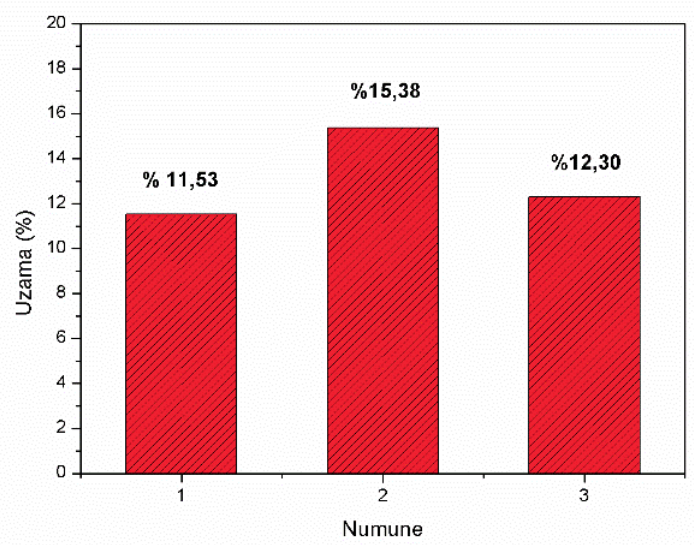

Şekil 6. Çekme testi sonrası numunelerin \%uzama değerleri.

\subsection{Vickers Sertlik Sonuçları}

Kaynak bölgesi merkez noktası olacak şekilde $3 \mathrm{~mm}$ aralıklarla toplamda 7 noktaya vuruş yapılmıştır. Sırasıyla ana metal bölgesi, ITAB, kaynak bölgesi, ITAB ve ana metal bölgesi sertlik değerleri ölçülmüştür. 3 bölgenin sertlik değerleri tüm numuneler için Şekil 7'de gösterilmiştir.

\subsection{Mikroyapı Görüntüleri}

Şekil 8'de TIG kaynaklı numunenin 5x büyütmedeki mikroyapıları gösterilmiştir. Kaynakla birleştirilen numunenin ana metal bölgesi,kaynak bölgesi ve ITAB Şekil 8(A)'da belirtilerek bu bölgelerin mikroyapıları verilmiş̧ir. $\% 50$ büyütme alınan mikroyapı görüntüleri Şekil 9'da gösterilmiştir. Bu görüntülerde tane sınırları ve poroziteler açıkça görülmektedir.

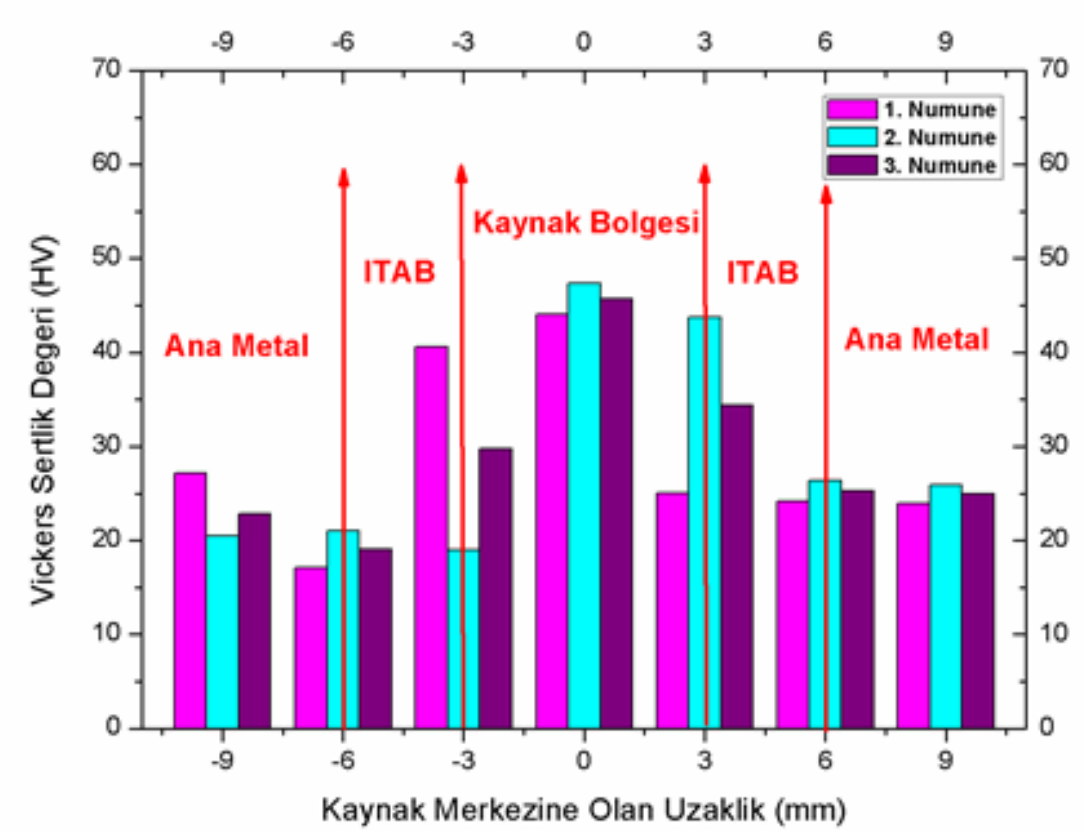

Şekil 7. Numunelerin ana metal, ITAB ve kaynak bölgesi sertlik değerleri. 


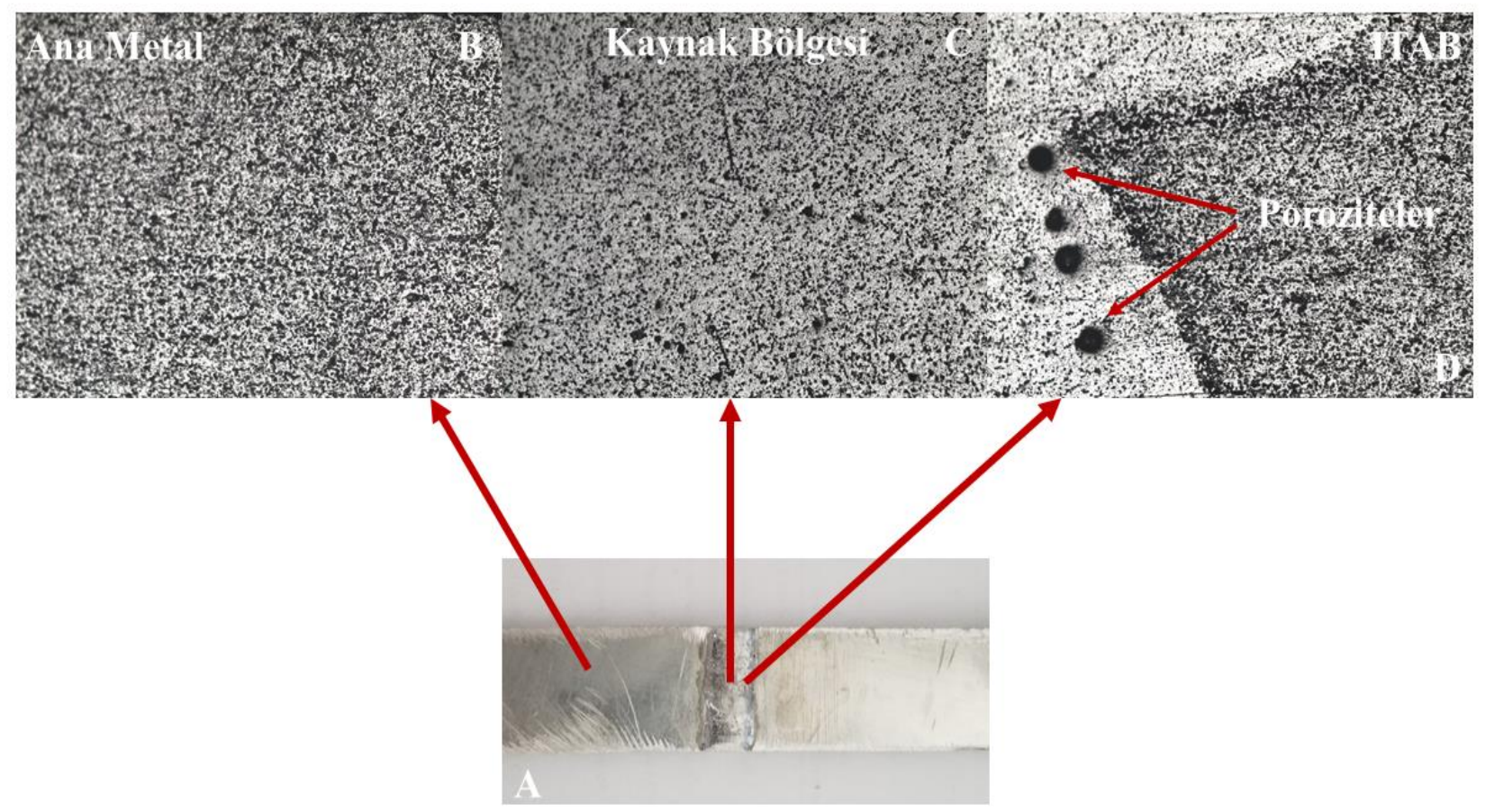

Şekil 8. TIG kaynağı ile birleştirilen numune(A), 5x büyütmedeki ana metal bölgesi(B), kaynak bölgesi(C) ve ITAB(D).
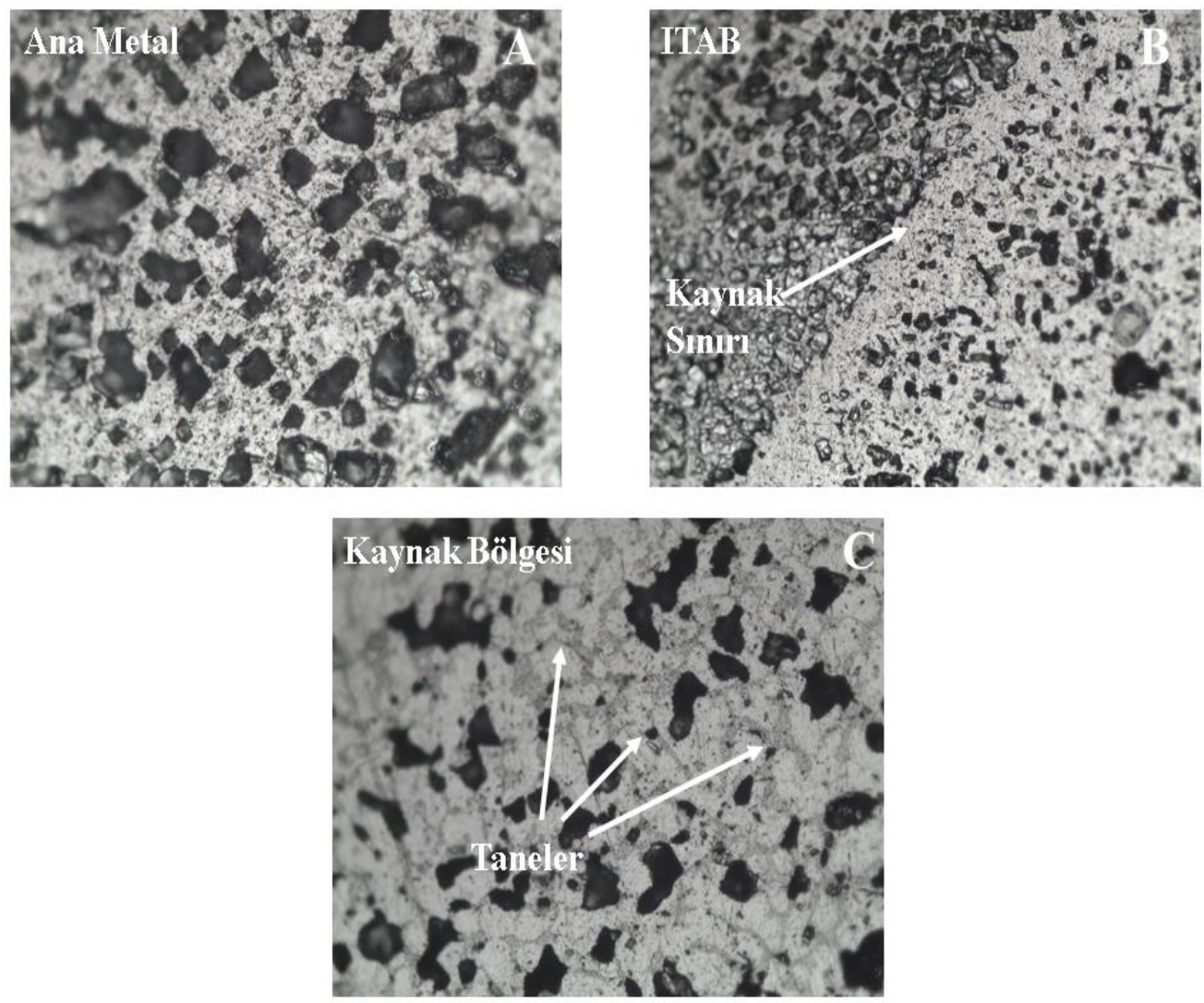

Şekil 9. 50x büyütmedeki kaynaklı numunelerin mikroyapı görüntüleri, ana metal(A), ITAB(B), kaynak bölgesi(C). 


\section{DEĞERLENDİRME VE SONUC}

Bu çalışmada TIG kaynak yöntemi ile birleștirilen Al 1050 alaşım levhaların mekanik ve mikroyapısal özellikleri incelenmiştir. Birleştirilen numunelere çekme ve sertlik testleri uygulanmıştır. Kaynak bölgesi ve çevresinin mikroyapıları optik mikroskop ile incelenmiştir.

Alüminyum sünek ve yumuşak bir metal olduğundan çekme testi sonrasında numuneler sünek kırılma davranışı göstermiştir. Kaynak bölgesi metali ana metal ve ısıdan etkilenen bölgeden daha sağlam ve sert olduğundan çekme sonrası numuneler kaynak metalinden değil ITAB'dan kopmuştur. Şekil 4'deki grafikten görüldügü üzere en yüksek gerilme dayanımı $62,23 \mathrm{~N} / \mathrm{mm}^{2}$ olarak belirlenmiştir. Ortalama gerilme dayanımı ise $61,13 \mathrm{~N} / \mathrm{mm}^{2}$ olarak hesaplanmıştır ve Şekil 5'deki grafikte gösterilmiştir. Kumar K. vd [8], yaptıkları çalışmada Al1050 alaşımını TIG yöntemi ile kaynaklamış ve çekme testi sonuçlarını 22.03 ile $55.828 \mathrm{MPa}$ arasında elde etmişlerdir. Bu çalışmada elde edilen çekme testi sonuçları daha yüksek olmuştur ve bu da yapılan kaynak işleminin daha düzgün olduğunu göstermektedir. Al 1050 alaşımının standart çekme dayanımı 65-80 Mpa'dır. Isıdan etkilenen bölgedeki düşük ısı girdisi ile birlikte gelişen yavaş soğumanın meydana getirdiği ve kaynak bölgesine oranla daha iri taneli olan mikroyapıdan dolayı bu bölgedeki mukavemette düşüş meydana gelmiştir. Kaynak bölgesine göre daha düşük mukavemetli olan ITAB'da çekme testi sırasında kopma meydana gelmiştir ve bu da numunelerin çekme dayanımlarında düşüşe neden olmuştur. Al 1050 alaşımı \%38'lik uzama oranlarına çıkabilen sünek bir metaldir. Fakat kaynak işlemi uygulanan alaşımda meydana gelen tane küçülmesiyle birlikte dayanımda bir artış meydana gelmektedir. Şekil 6'dan da görüldüğü üzere kaynaklı numunelerin uzama oranı en fazla \%15,38 olmuştur. El-Sayed M.A [9] yaptığı çalışmada A11050 alaşımına sürtünme kaynağ1 uygulamış ve test sonuçlarına göre ortalama \%9,5 elde etmiştir. Buna bakılarak \%15,38'lik uzama değeri bize yapılan kaynak işleminin uzama oranını az miktarda etkilediğini ve alüminyum alaşımının sahip olduğu esnekliği koruyabildiğini göstermiştir. Isı tesiri altındaki bölgenin ana metale göre daha sert olması numunelerin uzama oranlarını düşürmüştür.

Kaynaklı numunelere uygulanan Vickers sertlik sonuçları incelendiğinde kaynak merkezlerinin en yüksek sertlik değerlerine sahip oldukları görülmüştür. Vickers sertlik değeri 25-30 HV arasında değişen Al 1050 alaşımının kaynak bölgesi sertlik değerleri 44-47 HV arasında bulunmuştur. Şekil 7'ye bakıldığında ana metal bölgesinden kaynak merkezine doğru ilerledikçe sertlik değerlerinde bir artış gözlenmektedir. Alves E.P vd [23] de yaptıkları çalışmada birleşme bölgesinin sertlik değerlerinin ana metale oranla daha yüksek olduğunu göstermiştir. En düşük sertlik değerine sahip bölge en yumuşak yapıda olan ana metal bölgesidir. Kaynak bölgesindeki sertlik artışının sebebi olarak yüksek 1sı girdisiyle birlikte hızlı oluşan hızlı katılaşma sonucu alfa alüminyum tanelerinin daha küçük ve ince yapıda meydana gelmesi gösterilebilir.
Optik mikroskop görüntüleri incelendiğinde kaynak bölgesinde ve ITAB'da porozitelerin bulunduğu görülmüştür. Şekil 8(D)'de gösterilen, koruyucu gazların kaynak işlemi sırasında metal içerisinde sıkışmasıyla oluşan bu poroziteler metalin mukavemetinde ve sertliğinde azalmalara yol açabilmektedir. Kaynak sonrası meydana gelen mikroyapılar incelendiğinde kaynak bölgesinin ana metale göre daha ince taneli bir yapıya sahip olduğu Şekil 9(B)'de görülmüştür. Kumar K. vd [8], yaptıkları çalışmada ana metal ve kaynak bölgesinin mikroyapı değişimimlerini göstermiştir ve kaynak bölgesinde oluşan ince taneli yapının kaynak esnasında meydana gelen sıcaklık değişimlerinden oluştuğunu açıklamıştır. Oluşan tane ve tane sınırları Şekil 9(C)'de açıkça görülmektedir. Kaynak bölgesinde oluşan ince taneli yapı kaynak metalinin çekme mukavemetinin ve sertliğinin artmasını sağlamıştır.

Yapılan bu çalışmadan elde edilen sonuçlar şu şekilde sıralanmıştır;

1) TIG kaynak yöntemi ile birleştirilen Al 1050 alaşımının kaynak bölgesi dikişinin oldukça temiz olduğu porozitelerin en az seviyede olmasından anlaşılabilmektedir.

2) Kaynak bölgesinde oluşan porozite ve oksitlenme miktarının oldukça az olduğu görülmüştür.

3) Birleştirme işlemi sonrasında alaşımın kaynak bölgesinin çekme mukavemeti ve vickers sertliğinde artış meydana geldiği belirlenmiştir.

4) Numunelerin mikroyapıları incelendiğinde kaynak bölgesinden tanelerin küçüldüğü ve daha dentritik bir yapıya dönüştükleri görülmüştür.

5) Al 1050 alaşımının TIG yöntemi ile kaynak uygulaması sonucunda numunelerin birleşme bölgelerinde çekme mukavemeti artmıştır, numunelerin uzama değerleri Al 1050 alaşımı değerleri kadar iyi çıkmıştır.

\section{KAYNAKÇA}

[1].Baskutis S., Baskutiene J., Bendikiene R., and Ciuplys A., Effect of weld parameters on mechanical properties and tensile behavior of tungsten inert gas welded AW6082-T6 aluminium alloy, J. Mech. Scl. Technol. 33(2): 765-772, 2019.

[2].Taban E., and Kaluc E., Microstructural and mechanical properties of double-sided MIG, TIG and friction stir welded 5083-H321 aluminium alloy, Kovove Mater. 44: 25-33, 2006.

[3].Liu L., Ren D., and Liu F., A Review of Dissimilar Welding Techniques for Magnesium Alloys to Aluminum Alloys, Mater. 7: 3735-3757, 2014.

[4].Lin S.B., Song J.L., Ma G.C., Yang C.L., Dissimilar metals TIG welding-brazing of aluminum alloy to galvanized steel, Front. Mater. Sci. China 3(1): 78-83, 2009.

[5].Tušek J., Klobčar D., Tungsten inert gas (TIG) weldıng of aluminum alloy en $\mathrm{AW}-\mathrm{AlZn} 5.5 \mathrm{MgCu}$, Metalurgija 55(4): 737-740, 2016.

[6].Çetinkaya C., Tekeli S., Kurtuluş O., Alüminyum Alaşımlarının Kaynaklanabilirliği Ve Kaynak 
Parametrelerin Mekanik Özelliklere Ve Mikroyapıya Etkisi, Politeknik Dergisi 5(4): 321-333, 2002.

[7].Luijendijk T., Welding of dissimilar aluminium alloys, $J$. Mater. Process Tech. 103: 29-35, 2000.

[8].Kumar K., Mohan P., Masanta M., Influence of welding current on the mechanical property of $3 \mathrm{~mm}$ thick commercial 1050 aluminium butt joint weld by AC-TIG welding method, Mater. Today: Proc. 5: 24141-24146, 2018.

[9].El-Sayed M.A., Effect of Welding Conditions on the Mechanical Properties of Friction Stir Welded 1050 Aluminum Alloy, Internat. Rev. of Mech. Engin. 9(3): 252256, 2015.

[10]. Schubert E., Challenges in Thermal Welding of Aluminium Alloys, World J. of Engin. and Tech. 6: 296303, 2018.

[11]. Kara R., Yıldırım G., Çolak F., ve Tınas M., TIG ve Elektrik Ark Kaynağı ile Birleştirilen Alüminyum Plakaların Mekanik Özelliklerinin İncelenmesi, El-Cezerî J. of Sci. and Engin. 4(2): 274-281, 2017.

[12]. Empo aluminium, EN AW 1050 ürün özellikleri, URL; http://www.empo.com.tr/aluminyum-levha/en-aw-

1050.html (Erişim Zamanı; Haziran 6, 2020).

[13]. Durgutlu A., Alüminyumun TİG Kaynağında Akım Türünün Kaynak Metali Mikroyapısı ve Darbe Dayanımına Etkisi, Gazi Üni. Müh. ve Mimar. Fak. Derg. 24(1): 155-160, 2009.

[14]. Patil P.C., Shelke R.D., Review On Weldıng Parameter Effects On TIG Weldıng of Alumınıum Alloy, Internat. J. of Engin. Res. and Gen. Sci. 3(3): 1479-1486, 2015.

[15]. KumarSingh S., Tiwari R.M., Kumar A., Kumar S., Murtaza Q., and Kumar S., Mechanical Properties and
Micrstructure of Al-5083 by TIG, Mater. Today: Proc. 5: 819-822, 2018.

[16]. Manti R., Dwivedi D.K., and Agarwal A., Pulse TIG Welding of Two Al-Mg-Si Alloys, J. of Mater. Engin. and Perfor. 17:667-673, 2008.

[17]. Kumar A., and Sundarrajan S., Optimization of pulsed TIG welding process parameters on mechanical properties of AA 5456 Aluminum alloy weldments, Mater. and Design 30: 1288-1297, 2009.

[18]. Durgutlu A., Kahraman N., Gülenç B., Al - Si Alaşımının TİG Kaynağında Darbeli Akımın Mikroyapı, Sertlik, Eğme ve Çekme Dayanımına Etkisi, Politeknik Dergisi 11(4): 339-344, 2008.

[19]. Tarng Y.S., Tsai H.L., Yeh S.S., Modeling, Optimization And Classification of Weld Quality in Tungsten Inert Gas Welding, Internat. J. of Mach. Tools \& Manuf. 39: 1427-1438, 1999.

[20]. Ayvaz M., ve Çetinel H., Farklı Alüminyum Alaşımlarının, TIG Kaynak Yöntemi ile Kaynatılması ve Mekanik Özelliklerinin İncelenmesi, Celal Bayar Üniv. Fen Bilim. Derg. 7(1): 39-46, 2011.

[21]. Durgutlu A., Alüminyumun TIG Kaynağında ArgonHidrojen Gaz Karışımının Mikroyapı ve Mekanik Özelliklere Etkisi, Politeknik Dergisi 10(3) : 271-276, 2007. [22]. Khotiyan S.K., Kumar S., Investigation of Microstructure and Mechanical Properties of TIG and MIG Welding Using Aluminium Alloy, Internat. J. of Educ. and Sci. Res. Review 1(5): 90-96, 2014.

[23]. Alves E.P., Neto F.P., Welding of AA1050 aluminum with AISI 304 stainless steel by rotary friction welding process, J. Aerosp.Technol. Manag., São José dos Campos, 2(3): 301-306,2010. 